\title{
Article \\ Factors That Shape Women's Physical Activity: Development of the Reasons to Participate in Physical Activity Scale (RPPAS)
}

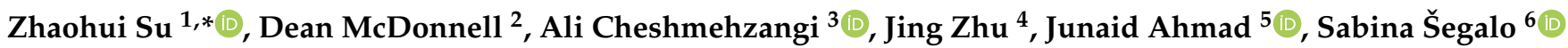 \\ and Claudimar Pereira da Veiga ${ }^{7, *(\mathbb{D})}$
}

1 Center on Smart and Connected Health Technologies, Mays Cancer Center, School of Nursing, UT Health San Antonio, San Antonio, TX 78229, USA

2 Department of Humanities, Institute of Technology Carlow, R93 V960 Carlow, Ireland; dean.mcdonnell@itcarlow.ie

3 Faculty of Science and Engineering, University of Nottingham Ningbo China, Ningbo 315100, China; Ali.Cheshmehzangi@nottingham.edu.cn

4 Beijing Institute of Nutritional Resources, Beijing 100069, China; jingzhu.nutri@outlook.com

5 Prime Institute of Public Health, Peshawar Medical College, Peshawar 25160, Pakistan; Jahmad@piph.prime.edu.pk

6 Department of Microbiology, Faculty of Medicine, University of Sarajevo, 71000 Sarajevo, Bosnia and Herzegovina; sabina.segalo11@gmail.com

7 School of Management-PPGOLD, Federal University of Parana-UFPR, Curitiba 80210-170, Brazil

* Correspondence: szh@utexas.edu (Z.S.); claudimar.veiga@ufpr.br (C.P.d.V.)

check for

updates

Citation: Su, Z.; McDonnell, D.;

Cheshmehzangi, A.; Zhu, J.; Ahmad, J.; Šegalo, S.; da Veiga, C.P. Factors That Shape Women's Physical Activity: Development of the Reasons to Participate in Physical Activity Scale (RPPAS). Healthcare 2022, 10, 94. https://doi.org/ 10.3390/healthcare10010094

Academic Editor: Roberta Ferrucci

Received: 15 October 2021

Accepted: 29 December 2021

Published: 4 January 2022

Publisher's Note: MDPI stays neutral with regard to jurisdictional claims in published maps and institutional affiliations.

Copyright: (C) 2022 by the authors. Licensee MDPI, Basel, Switzerland. This article is an open access article distributed under the terms and conditions of the Creative Commons Attribution (CC BY) license (https:// creativecommons.org/licenses/by/ $4.0 /)$.

\begin{abstract}
Background: Obesity could deepen women's susceptibility to COVID-19 infections and deaths. While physical activity has the potential to improve women's physical and psychological resilience to the pandemic, there is a dearth of research on factors that motivate women's participation in physical activity. Thus, to bridge the research gap, this study aims to identify factors that motivate women's participation in physical activity. (2) Methods: An online survey on motivations for physical activity was developed and distributed to the participants. A total of 108 women offered complete answers $\left(N=108,18-33\right.$ years old, $\mathrm{M}_{\text {age }}=20.34 \pm 2.42$ years $)$. Participants selected factors that promote their physical activity from a list of 34 factors from the Reasons to Participate in Physical Activity Scale (RPPAS) developed in this study. (3) Results: Exploratory factor analysis revealed that factors that motivate women's participation in physical activity are: enjoyment and gratification, consideration for other activities (i.e., exergaming), health benefits, networking opportunities, and appearance and performance. Multiple linear regression analyses indicate that only consideration for appearance and performance was significantly associated with participants' physical activity levels after controlling for compounding factors. (4) Conclusions: The findings of this study underscore the importance of appearance and performance in shaping women's participation in physical activity. Furthermore, the results also emphasize the need for a nuanced understanding of factors that influence women's physical activity levels. Future research could investigate how to leverage these motivators in tailored health interventions that aim to improve women's physical activity.
\end{abstract}

Keywords: physical activity; women; factor analysis; obesity; health disparities; COVID-19; pandemic

\section{Background}

A world without women is a world without a future. Women's roles in childbearing, caregiving, and the workforce are indispensable to the integrity of society [1]. However, while the health of women shapes the wellbeing of humanity, women shoulder a wide array of health challenges that could substantially compromise their abilities to care for themselves and contribute to society [2]. Data suggest that, for instance, while $6.9 \%$ of men 20 years and older in the U.S. face severe obesity, $11.5 \%$ of women suffer the same condition [3], which means that women are more likely than their male counterparts to develop obesity-induced morbidity and mortality risks [4-7]. Take cancer, for instance: 
Research shows that while $25 \%$ of cancers diagnosed in men are overweight- and obesityrelated cancers, the prevalence of these cancers among women is 55\% [8]. COVID-19 could further compound the situation. In an analysis of 502,493 people (54\% women), researchers found that a higher body mass index (BMI) is linked with greater risks of COVID-19 deaths in women than men [9]. In addition, researchers also found that the pandemic not only exacerbated the deep-rooted health disparities women face before the pandemic (e.g., limited access to healthcare services), it also introduced new challenges women need to shoulder, ranging from pronounced financial insecurity, an unprecedented surge of domestic violence, to health issues that are unique to women [10-12].

These insights combined, in turn, highlight the imperative to address the obesity epidemic in women, particularly amid COVID-19. One cost-effective approach that could reduce women's susceptibility to health consequences of obesity, along with their vulnerability to COVID-19, is physical activity [13-19]. Physical activity broadly refers to the bodily movement of skeletal muscles that results in the expenditure of energy [20]. Mounting evidence suggests that physical activity is critical to people's physical and mental health [21-23]. A longitudinal study conducted prior to the pandemic, for instance, shows that habitual physical activity positively impacts fat formation in adolescence and fat growth in adulthood [21], health improvements that are critical to maintaining physical health. Research conducted amid the pandemic further shows that physical activity can reduce people's anxiety and boost their mood during COVID-19 [24], including periods of lockdowns [16-19].

However, though physical activity has great potential to help women fend off the adverse impacts of COVID-19 and beyond, women's physical activity levels are suboptimal. A study of 1.9 million participants worldwide conducted prior to the pandemic shows that $31.7 \%$ of women, compared to $27.5 \%$ of men, have insufficient physical activity levels [25]. Analyses of data on 212,021 people from 51 countries further show that $20 \%$ of women, as opposed to $15 \%$ of men, are at heightened risks for chronic diseases due to physical inactivity [26], the gap which was confirmed by subsequent research [27]. The pandemic has further compounded the situation. Analyzing physical activity changes of 455,404 people from 187 countries between 19 January 2020 and 1 June 2020, researchers found that, though to varying degrees, the pandemic has reduced people's physical activity levels across the world [24].

One way to boost women's physical activity levels, as insights from value-expectancy theories [28-31] and persuasive communication literature [32-34] suggest, is via understanding what factors motivate women to participate in physical activity the most, and in turn, integrate these factors into tailored health interventions to boost women's participation in physical activity. However, while useful insights are available, there is a lack of research on factors that motivate young females to improve their physical activity levels. Thus, to bridge the literature, this study aims to identify factors that motivate young women's participation in physical activity that could help guard tailored intervention design and development.

\section{Methods}

\subsection{Participants and Procedure}

This study was approved by the University's Institutional Review Board (IRB). It was part of a larger study that examines people's physical activity behavior in light of technological alternatives such as exergaming (video-game-based exercise) [35]. Participants were recruited from Southwestern University's large participant pool and were asked to read and agree to the consent form prior to participation. A written consent form was waived by the IRB office, and a digital variation was used. The survey was distributed online between March to May 2014, powered by the Qualtrics survey platform, and consists of both fixed and open-ended questions that examine people's physical activity and exergaming behavior. 
Specifically, respondents were asked to report their sociodemographic background, factors that promote their physical activity, and leisure-time physical activity levels. All participants were informed regarding their rights prior to joining the study, including being able to withdraw from the research at any time without question. Detailed information on all the female and male participants' sociodemographic and personal characteristics could be found in Table 1. Among all the respondents who participated in the study, we excluded those who did not self-identify as female and offered incomplete answers.

Table 1. Descriptive statistics of all female and male participants.

\begin{tabular}{cc}
\hline Variable & Total (\%) \\
\hline N & $403(100.0)$ \\
Age (years, Mean \pm SD) & $20.2( \pm 2.3)$ \\
Gender & $108(26.8)$ \\
Male & $295(73.2)$ \\
Female & \\
Race & $235(58.3)$ \\
White & $168(41.7)$ \\
Non-White & \\
Income & $83(21.0)$ \\
$\sim$ USD 19,999 & $103(26.0)$ \\
USD 20,000 USD 74,999 & $210(53.0)$ \\
USD 75,000 & $22.3( \pm 3.1)$ \\
BMI (kg/m ${ }^{2}$, Mean \pm SD) & $57.5( \pm 56.1)$ \\
Leisure-time physical activity &
\end{tabular}

\subsection{Development of Scale Items}

Scales, namely, the Reasons to Participate in Physical Activity Scale (RPPAS), utilized to gauge factors that promote women's physical activity were developed based on theoretical frameworks from behavioral sciences [28-31] and existing literature on physical activities [36-39]. Two experts developed the RPPAS scales (in addition to the author, one professor whose research centers on physical activity and exergaming). Drawing insights from the literature (e.g., [40,41]), we adopted the term "traditional exercise" to refer to an activity requiring physical effort, carried out to sustain or improve health and fitness with little to no dependence on technology, whereas exergaming is defined as video games that require substantial bodily movement to play and function. Participants were recruited to evaluate the preliminary scales. Discrepancies were resolved by rounds of group discussions that involve both the experts and participants until a consensus was reached. The final scale includes 34 factors that shape people's physical activity. Prior to distribution, the survey was first piloted in a group of individuals who were not familiar with the research to further examine its validity. The RPPAS scale items received positive reviews and were subsequently adopted in the online survey. Detailed information on scale development could be found in Figure 1. 


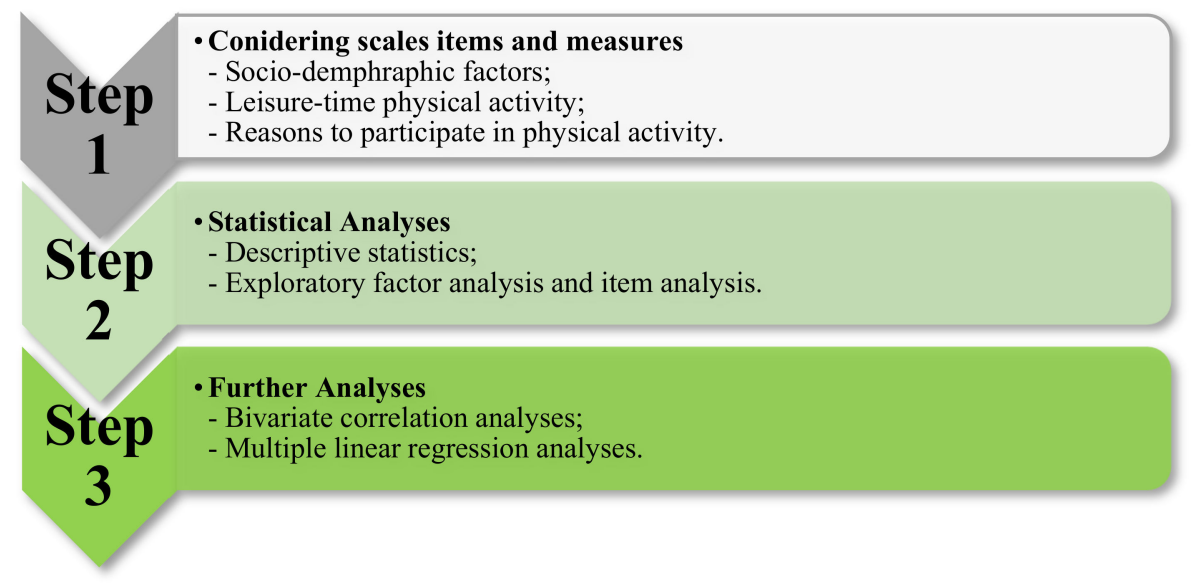

Figure 1. Scale development procedures.

\subsection{Measures}

\subsubsection{Sociodemographic Factors}

Age and body mass index (BMI) were measured as continuous variables. For the study, race was coded as 1 for Hispanic, 2 for White, 3 for African American, 4 for Asian, and 5 for Others.

\subsubsection{Leisure-Time Physical Activity}

Participants were asked how often they engaged in vigorous (e.g., running, jogging, hockey, football, soccer, squash, basketball, vigorous swimming, vigorous long-distance bicycling), moderate (e.g., fast walking, baseball, tennis, easy bicycling, volleyball, badminton, easy swimming), and mild exercise (i.e., yoga, archery, fishing from river band, bowling, horseshoes, golf) per week during their leisure time. Leisure-time physical activity was measured by calculating as follows: (Times of vigorous physical activity $\times 9)+($ Times of moderate physical activity $\times 5)+($ Times of mild physical activity $\times 3)(\mathrm{MET})$ [42].

\subsubsection{Reasons to Participate in Physical Activity}

Participants' motivation for engaging in physical activity was measured by the "Reasons to Participate in Physical Activity" questionnaire developed in the current study. Respondents were asked to rate items such as: "I exercise because it's a great way to pass time," "I exercise because it's an entertaining experience," and "I exercise because I think it helps me lose weight" on a 7-point scale, from 1 (strongly disagree) to 7 (strongly agree) (Cronbach's alpha $=0.96$ ).

\subsection{Statistical Analyses}

The analyses for this study were conducted using SPSS 24.0 (IBM SPSS Statistics for Mac, Version 24.0, IBM, Armonk, NY, USA). First, descriptive statistics were conducted and analyzed. Second, exploratory factor analysis and item analysis were performed to examine the preliminary construct validity and internal consistency reliability of the 34 items. Bartlett's sphericity test and Kaiser's Measure of Sampling Adequacy were computed to determine the appropriateness of conducting principal components analysis for this data set. Exploratory factor analyses were calculated using principal components analysis with oblique rotation to identify the factor structure. Factor loadings of 0.30 or higher were viewed as acceptable target factor loadings [43]. Finally, bivariate correlation analyses and multiple linear regression analyses were conducted to examine the association of different factors of reasons to participate in physical activity to leisure-time physical activity levels among female college students. 


\section{Results}

A total of 108 college female students $\left(M_{\text {age }}=20.34, S D=2.42\right)$ were recruited from a large southwestern university. The sample comprised 64 (58.2\%) White, 20 (18.2) Hispanic, $16(14.5 \%)$ Asian, 7 (6.4\%) African American women, and 3 (2.7\%) Others. There were $28(25.5 \%)$ sophomores, $28(25.5 \%)$, juniors $(n=63,21.4 \%), 28(25.5 \%)$ seniors, $21(19.1 \%)$ freshmen, and 5 (4.5\%) postgraduates. The participants' average of both BMI and leisuretime physical activity were $22.10 \pm 2.83\left(\mathrm{~kg} / \mathrm{m}^{2}\right)$ and $52.34 \pm 29.84(\mathrm{MET})$, respectively.

\subsection{Exploratory Factor Analysis}

The initial exploratory factor analysis was conducted based on a sample of 108 female college students. Several well-recognized criteria for the factor analysis were used. First, it was observed that all 34 items were significantly correlated, suggesting reasonable associations for factor analysis. Second, the Kaiser-Meyer-Olkin measure of sampling adequacy was 0.89 , above the commonly recommended value of 0.60 [44], and Bartlett's test of sphericity was significant $(\chi 2(561)=3762.61, p<0.001$; Bartlett [45]). The diagonals of the anti-image correlation matrix were also all over 0.80 . Finally, the commonalities were all above 0.30 (Table 1), further confirming that each item shared some common variance with other items. Given these overall indicators, it was sufficient to conduct factor analysis with all 34 items.

Principal component analysis was used because the primary purpose was to identify the factors underlying the reason to participate in physical activity. Initial eigenvalues indicated that the first five factors explained $47 \%, 14 \%, 7 \%, 5 \%$, and $4 \%$ of the variance, respectively. The solution for the five factors was examined using oblimin rotations of the factor loading matrix. The five-factor solution, which explained $77 \%$ of the variance, was preferred based on the scree plot, eigenvalues, and qualitative interpretation. All items in this analysis had primary loading of at least 0.30 . The factor loading matrix for this solution is presented in Table 2.

\subsection{Item Analysis}

Internal consistency for each of the items was examined using Cronbach's alpha. Cronbach's alpha $\geq 0.70$ was considered adequate internal consistency [46]. Factor 1, labeled enjoyment and gratification, included 12 items with Cronbach's alpha $=0.96$. Factor 2 was labeled as Consideration for other activities (i.e., exergaming) and included five items with Cronbach's alpha $=0.96$. Factor 3, health benefits, consisted of five items with Cronbach's alpha $=0.90$. Factor 4 , networking opportunities included seven items with Cronbach's alpha $=0.92$. Finally, Factor 5, appearance and performance, consisted of five items with Cronbach's alpha $=0.91$. The skewness and kurtosis were well within a tolerable range for assuming a normal distribution (Table 3). Overall, these analyses indicated that underlying college female students' responses were organized into five distinct factors on the reasons to participate in physical activity items and that these factors were strongly internally consistent.

\subsection{Bivariate Correlation and Multiple Linear Regression}

Overall, enjoyment and gratification $(r=0.54, p<0.001)$, consideration for other activities (i.e., exergaming) $(r=0.21, p<0.05)$, health benefits $(r=0.26, p<0.01)$, networking opportunities $(r=0.44, p<0.001)$, and appearance and performance $(r=0.49, p<0.001)$ were significantly associated with leisure-time physical activity. Multiple linear regression analyses were used to examine the association of five different factors to leisure-time PA. The results showed that appearance and performance was uniquely associated with leisuretime PA $(\beta=0.37, p=0.012)$, after controlling for age, race/ethnicity, and BMI. However, enjoyment and gratification, consideration for other activities (i.e., exergaming), health benefits, and networking opportunities were not associated with leisure-time physical activity. 
Table 2. Factor loadings and communalities for 34 items from RPPAS.

\begin{tabular}{|c|c|c|c|c|c|c|}
\hline Items & Factor 1 & Factor 2 & Factor 3 & Factor 4 & Factor 5 & Communalities \\
\hline 4. Doing exercise gives me pleasure. & 0.92 & & & & & 0.84 \\
\hline 6. I consider myself as an avid exerciser. & 0.87 & & & & & 0.80 \\
\hline 2. I exercise to unwind. & 0.85 & & & & & 0.81 \\
\hline 3. I exercise because it's an entertaining experience. & 0.84 & & & & & 0.77 \\
\hline $\begin{array}{l}\text { 7. Being good at doing exercise has become an } \\
\text { identity to me. }\end{array}$ & 0.81 & & & & & 0.77 \\
\hline 1. I exercise because it's a great way to pass time. & 0.79 & & & & & 0.62 \\
\hline 9. I exercise because it's addictive. & 0.76 & & & & & 0.69 \\
\hline 5. I like to escape in my exercise. & 0.75 & & & & & 0.77 \\
\hline 8. I feel related to other people when I exercise. & 0.58 & & & & & 0.63 \\
\hline 10. I feel I'm in control when doing exercise. & 0.49 & & & & & 0.70 \\
\hline 20. I take pride in my exercise skills. & 0.43 & & & & & 0.76 \\
\hline $\begin{array}{l}\text { 17. Doing exercise gives me a sense of accomplishment. } \\
\text { 32. I exercise and play active games at the same time }\end{array}$ & 0.30 & & & & & 0.64 \\
\hline $\begin{array}{c}\text { because I want to improve my exercise performance in } \\
\text { active gaming. }\end{array}$ & & 0.96 & & & & 0.92 \\
\hline $\begin{array}{l}\text { 33. I exercise to learn more about active gaming } \\
\text { skills and methods. }\end{array}$ & & 0.93 & & & & 0.93 \\
\hline $\begin{array}{l}\text { 31. I exercise because I like the active gaming and want to } \\
\text { play more of it. }\end{array}$ & & 0.92 & & & & 0.87 \\
\hline $\begin{array}{l}\text { 34. I exercise to work on my form for active } \\
\text { gaming techniques. }\end{array}$ & & 0.91 & & & & 0.87 \\
\hline 30. I exercise to improve my sports skills in active gaming. & & 0.85 & & & & 0.78 \\
\hline $\begin{array}{l}\text { 27. For me, traditional exercise costs less, compared to other } \\
\text { forms of exercise (e.g., active gaming), which may require } \\
\text { certain devices or gadgets. }\end{array}$ & & & 0.94 & & & 0.84 \\
\hline $\begin{array}{l}\text { 28. Doing traditional exercise is a quicker form of exercise } \\
\text { than other exercise methods (e.g., active gaming). }\end{array}$ & & & 0.91 & & & 0.82 \\
\hline $\begin{array}{l}\text { 29. I exercise because they fit better into my schedule over } \\
\text { other exercise methods (e.g., active gaming). }\end{array}$ & & & 0.76 & & & 0.66 \\
\hline $\begin{array}{l}\text { 26. Traditional exercise offers more varieties of easily } \\
\text { accessible exercise choices than other forms of exercise (e.g., } \\
\text { active gaming). }\end{array}$ & & & 0.61 & & & 0.77 \\
\hline $\begin{array}{l}\text { 25. I exercise because it's more convenient, compared to } \\
\text { other exercise methods (e.g., active gaming). }\end{array}$ & & & 0.54 & & & 0.77 \\
\hline $\begin{array}{l}\text { 14. I think competing in various exercise methods with my } \\
\text { friends / family strengthens our relationships. }\end{array}$ & & & & 0.88 & & 0.81 \\
\hline $\begin{array}{l}\text { 18. I like to compete against my friends / family while } \\
\text { doing exercise. }\end{array}$ & & & & 0.86 & & 0.83 \\
\hline $\begin{array}{l}\text { 13. I always have a quality time with my friends / family } \\
\text { when we were doing exercise. }\end{array}$ & & & & 0.82 & & 0.66 \\
\hline 19. I like to dominate other players when doing exercise. & & & & 0.81 & & 0.75 \\
\hline $\begin{array}{l}\text { 12. I exercise because it's a great way to stay close to my } \\
\text { friends / family. }\end{array}$ & & & & 0.75 & & 0.62 \\
\hline $\begin{array}{l}\text { 16.Competing/winning while doing exercise gives me } \\
\text { great self-satisfaction. }\end{array}$ & & & & 0.74 & & 0.63 \\
\hline $\begin{array}{l}\text { 15. I exercise because I want to excel at certain } \\
\text { exercise practice. }\end{array}$ & & & & 0.45 & & 0.72 \\
\hline 23. I exercise because I think it helps me lose weight. & & & & & 0.97 & 0.83 \\
\hline 22. I exercise because I think it helps me stay fit. & & & & & 0.87 & 0.89 \\
\hline 24. Doing exercise improves my appearance. & & & & & 0.87 & 0.85 \\
\hline $\begin{array}{l}\text { 11. Doing exercise makes me feel I'm constantly } \\
\text { making progress. }\end{array}$ & & & & & 0.47 & 0.77 \\
\hline 21. I constantly try to reach new goals when doing exercise. & & & & & 0.47 & 0.71 \\
\hline
\end{tabular}

Note. Factor loadings $<0.3$ are suppressed. Factor $1=$ Enjoyment and gratification; Factor $2=$ Consideration for other activities (i.e., exergaming); Factor $3=$ Health benefits; Factor $4=$ Networking opportunities; Factor $5=$ Appearance and performance. $\mathrm{PA}=$ physical activity. 
Table 3. Descriptive statistics from exploratory factor analysis of the five factors $(N=108)$.

\begin{tabular}{cccccc}
\hline Factor & No. of Items & $\boldsymbol{M}(\boldsymbol{S D})$ & Skewness & Kurtosis & $\begin{array}{c}\text { Cronbach's } \\
\boldsymbol{\alpha}\end{array}$ \\
\hline Factor 1 & 12 & $4.33(1.56)$ & -0.52 & -0.64 & 0.96 \\
Factor 2 & 5 & $2.10(1.59)$ & 1.55 & 1.51 & 0.96 \\
Factor 3 & 5 & $4.91(1.51)$ & -0.78 & 0.32 & 0.90 \\
Factor 4 & 7 & $3.66(1.58)$ & -0.001 & -0.87 & 0.92 \\
Factor 5 & 5 & $5.48(1.42)$ & -1.51 & 2.24 & 0.91 \\
\hline
\end{tabular}

Note. Factor 1 = Enjoyment and gratification; Factor 2 = Consideration for other activities (i.e., exergaming); Factor $3=$ Health benefits; Factor $4=$ Networking opportunities; Factor $5=$ Appearance and performance. PA $=$ physical activity. $M=$ mean; $S D=$ standard deviation.

\section{Discussion}

This paper set out to identify factors that motivate women's participation in physical activity, insights that could help government and health officials to develop tailored interventions to improve women's physical activity and health outcomes. This is the first study that examined motivating factors of physical activity that are unique to the female population. Considering the dearth of health measures that are tailored to women's characteristics and interests $[47,48]$, it is our hope that the current study could inspire more research endeavors that aim to address the concerns and challenges women face in the context of physical activity and beyond. Based on research findings, a scale (i.e., RPPAS) that reflects the unique preferences of women in physical activity was developed. In addition to its women-centeredness, what is also unique about the RPPAS measurement centers on its inclusion of the potential impacts of digital health (i.e., exergaming) on women's physical activity participation. These research contributions are particularly important amid COVID-19, a critical and high-stake period of time [49] when conditions such as obesity-a prevalent health challenge women face-have further increased women's susceptibility to COVID-19 infections and deaths [5-7].

The main research objective was to investigate factors that motivate women's participation in physical activity. Drawing insights from the literature [28-31,36-39], we developed and validated a 34-item RPPAS scale to examine women's physical activity behavior in light of digital health considerations such as exergaming. The results from exploratory factor analysis revealed that enjoyment and gratification, consideration for other activities (i.e., exergaming), health benefits, networking opportunities, as well as appearance and performance considerations are considerations that have the potential to promote women's participation in physical activity. By adding novel insights to the literature, the findings of our study further extend the current understanding of what factors have the potential to promote physical activities in women.

Interestingly, while all five of these factors are motivations for women's physical activity, results from multiple linear regression analyses indicate that only consideration for appearance and performance was significantly associated with participants' physical activity levels after controlling for compounding factors (i.e., age, race/ethnicity, and BMI). Contrary to previous research, which indicates that appearance-related factors negatively impact women's exercise behaviors [36,37], the current study's findings underscore the critical role of appearance and performance-based considerations in shaping women's physical activity levels. Overall, this finding is in line with real-world phenomena seen amid the pandemic. As COVID-19 continues to evolve, emerging evidence shows that, due to factors such as social pressure about physical appearances, women were more likely to experience Zoom fatigue [50]. Ironically, the perceived social pressure, such as the need to wear makeup, above and beyond gender-neutral expectations such as professional attire, has also prompted women, especially women of color, to be more reluctant to return to the office compared to their male counterparts [51,52].

In light of these insights, one way to capitalize on the research findings without causing unintended consequences in women is via respectively integrating appearance and performance appeals in physical activity interventions for women, using the co-design 
method [53]. In other words, researchers should invite women in their design and development of the interventions that are targeted to this population. In light of the constraints posed by the pandemic, such as limitations on in-person meetings [54], another way to adopt the co-design method in developing women-specific physical activity interventions is via developing a theory-guided and evidence-based campaign and then gaining the key target audience's insights [55], such as the example campaign the authors developed in the current study (see Figure 2). A schematic representation of the proposed co-design model could be found in Figure 3. Overall, this iterative design method could include all stakeholders in deciding what the "final" representation of the intervention should be (e.g., Does the intervention representative of all body sizes and skin colors?), in light of its effectiveness and appropriateness.

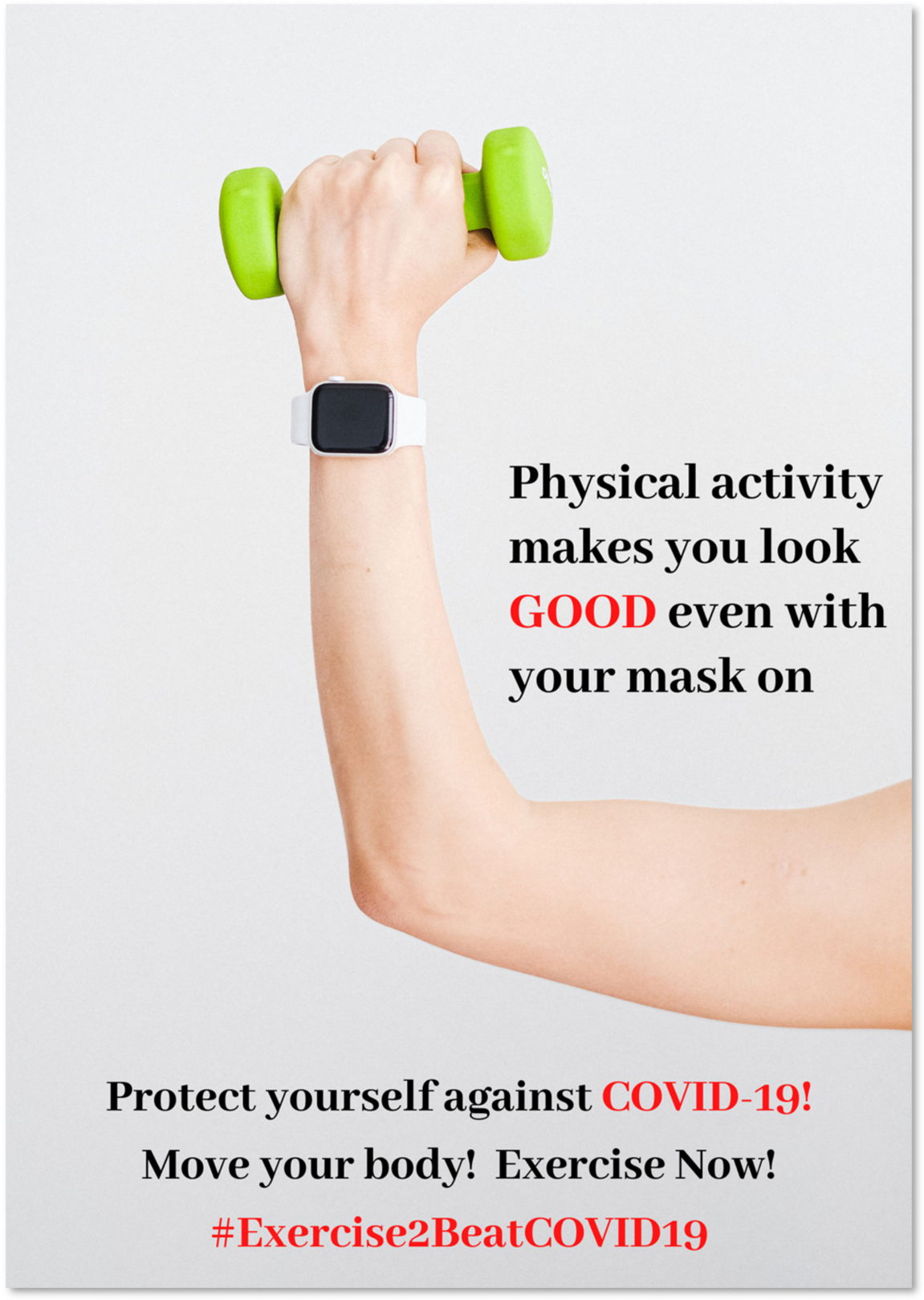

Figure 2. An example physical activity intervention. 


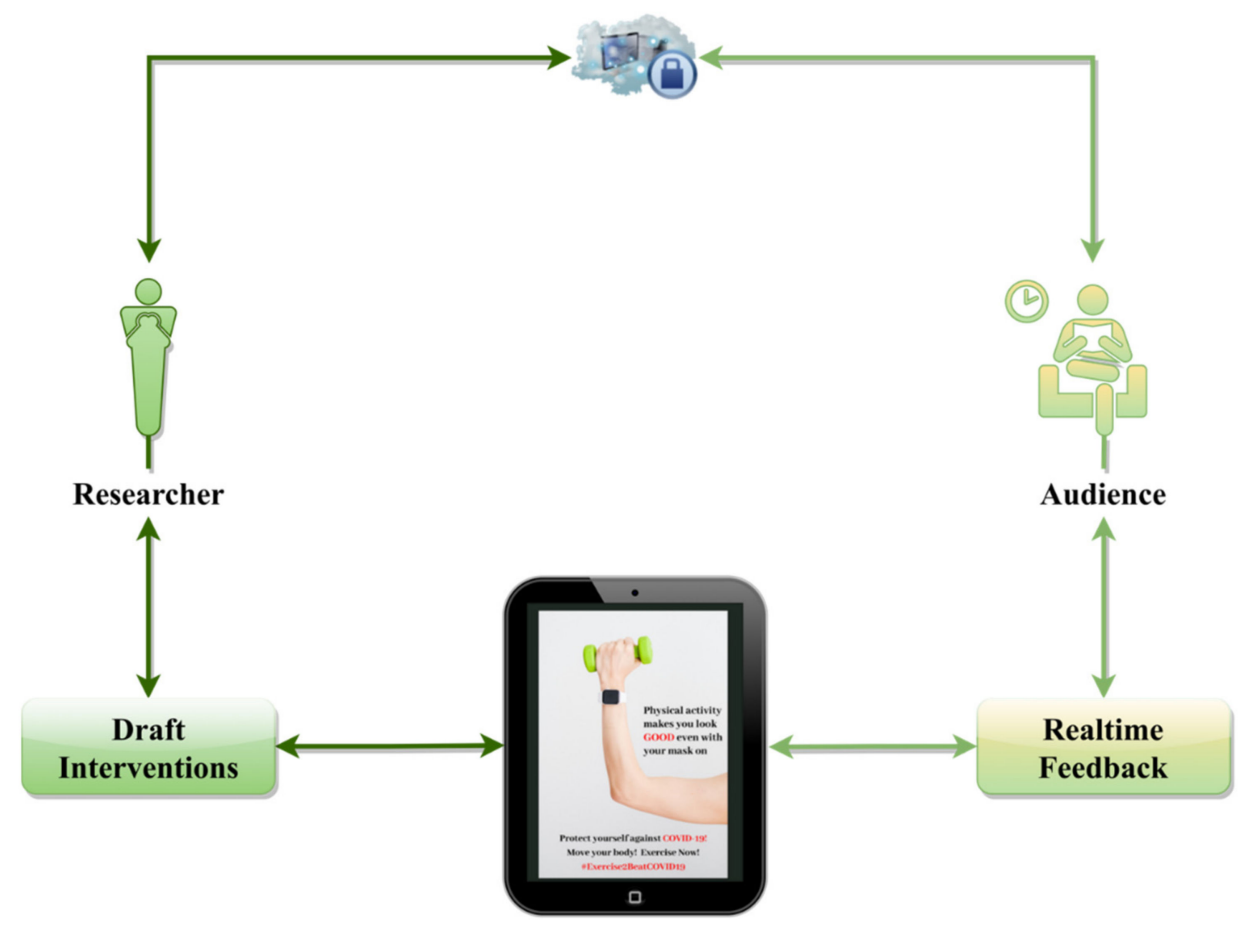

Figure 3. A schematic representation of the proposed co-design process.

People's physical activity has been substantially disrupted by COVID-19, particularly due to safety mandates such as lockdowns and social distancing [56-59]. In a study of 2524 Italian adults, researchers found that both men and women's physical activity significantly decreased amid the pandemic, the reduction of which is associated with the deterioration of participants' mental well-being [57]. Research on 2002 adults in the United Kingdom further shows that individuals with higher BMI and lower physical activity are more likely to face mental health issues amid lockdowns [15]. While there are challenges for people to access facilities such as gyms during the pandemic, there are substantial benefits associated with physical activity amid COVID-19 [16-19].

In a study of 2850 Spanish adults, for instance, findings show that amid shelter-athome mandates, participants who have greater physical activity experience lower levels of anxiety and mood swings [18]. Overall, these insights combined underscore the important implications of this study in informing physical activity intervention design and development for young women amid COVID-19. Future studies could explore ways to further leverage the importance of appearance and performance considerations for young women in physical activity interventions amid the pandemic, with the aim to alleviate potential physical and mental health challenges young women face during COVID-19.

Another reason why participatory design methods such as the co-design approach proposed in this study are important centers on the interplay between mental health and physical activity, particularly among women [60]. Existing evidence suggests that women often experience a greater scale and scope of mental health challenges, which could have an adverse impact on their participation in physical activity as well as overall health [61,62]. Mental health issues may also have a negative impact on women's interpretation of selfimage, along with considerations for appearance and performance (e.g., weight stigma), which may further compound women's physical activity participation [63-66]. The compounding impact of the pandemic should not be overlooked [67]. A study on mental health issues caused by COVID-19 further indicated that the pandemic has resulted in an additional 53.2 million cases of major depression and 76.2 million cases of anxiety disorders globally, both of which are more prevalent in women than men [68]. These insights, combined, paired with the potential added impacts of the Omicron variants [69], underscore the need to ethically and morally leverage the findings of the study—striving 
for optimal intervention outcomes without causing unintended consequences in women, as it is fundamental that interventions that aim to help do not incur harm.

\title{
Limitations
}

While this research fills important gaps in the literature, it is not without limitations. First, the survey developed in this study is self-administered by the participants, which suggests that results are subject to social desirability and recall biases. Second, this present study is cross-sectional in nature, indicating that findings are limited in their causal implications. Third, the sample size of the study is small, which could further impact the rigor of the research findings. Future research could address these limitations by inviting large and diverse female populations to participate in the study, preferably utilizing the longitudinal design, to further enrich the literature. Another limitation of our study is that we have yet to conduct a study to gauge the construct validity of the developed scale. We plan to address this limitation in our follow-up investigations.

\section{Conclusions}

A world without healthy women is a world without a promising future. Obesity and lack of physical activity are compromising women's abilities to care for themselves and their loved ones, as well as their capabilities to contribute to society. This study set out to identify factors that motivate women to participate in physical activity. Our findings underscored the importance of factors such as consideration for appearance and performance in shaping women's physical activity. Furthermore, the study results also emphasized the need for a nuanced understanding of influences that shape women's physical activity levels, ranging from concerns for enjoyment and gratification, consideration for other activities (i.e., exergaming), and health benefits to networking opportunities. Future research could investigate how to leverage these motivators in tailored health interventions that aim to improve women's physical activity.

Author Contributions: Z.S. conceived the work, reviewed the literature, and drafted and edited the manuscript; D.M., A.C., J.Z., J.A., S.Š. and C.P.d.V. reviewed the literature and edited the manuscript. All authors have read and agreed to the published version of the manuscript.

Funding: This research received no external funding.

Institutional Review Board Statement: Ethics approval and consent to participate: The University of Texas at Austin Institutional Review Board Exempt Protocol 2014-03-0021.

Informed Consent Statement: Not applicable.

Data Availability Statement: Data are available upon request.

Acknowledgments: The authors wish to express their gratitude to the editor and reviewers for their insightful feedback and constructive input. Special thanks go to Yen Chen for her kind support.

Conflicts of Interest: The authors declare no conflict of interest.

\author{
Abbreviations \\ BMI body mass index \\ IRB Institutional Review Board \\ RPPAS Reasons to Participate in Physical Activity Scale
}

\section{References}

1. Ardener, E. Defining Females: The Nature of Women in Society; Wiley: New York, NY, USA, 1978.

2. Matheson, A.; Kidd, J.; Came, H. Women, patriarchy and health inequalities: The urgent need to reorient our systems. Int. J. Environ. Res. Public Health 2021, 18, 4472. [CrossRef]

3. Hales, C.M.; Carroll, M.D.; Fryar, C.D.; Ogden, C.L. Prevalence of Obesity and Severe Obesity among Adults: United States, 2017-2018; NCHS Data Briefe; The Centers for Disease Control and Prevention: Atlanta, GA, USA, 2020; pp. 1-8. 
4. Nyberg, S.T.; Batty, G.D.; Pentti, J.; Virtanen, M.; Alfredsson, L.; Fransson, E.I.; Goldberg, M.; Heikkilä, K.; Jokela, M.; Knutsson, A.; et al. Obesity and loss of disease-free years owing to major non-communicable diseases: A multicohort study. Lancet Public Health 2018, 3, e490-e497. [CrossRef]

5. Stokes, E.K.; Zambrano, L.D.; Anderson, K.N.; Marder, E.P.; Raz, K.M.; Felix, S.E.B.; Tie, Y.; Fullerton, K.E. Coronavirus Disease 2019 Case Surveillance-United States, January 22-May 30, 2020. Morb. Mortal. Wkly. Rep. 2020, 69, 759-765. [CrossRef]

6. Williamson, E.J.; Walker, A.J.; Bhaskaran, K.; Bacon, S.; Bates, C.; Morton, C.E.; Curtis, H.J.; Mehrkar, A.; Evans, D.; Inglesby, P.; et al. Factors associated with COVID-19-related death using OpenSAFELY. Nature 2020, 584, 430-436. [CrossRef]

7. Libster, R.; Pérez Marc, G.; Wappner, D.; Coviello, S.; Bianchi, A.; Braem, V.; Esteban, I.; Caballero, M.T.; Wood, C.; Berrueta, M.; et al. Early high-titer plasma therapy to prevent severe COVID-19 in older adults. N. Engl. J. Med. 2021, 384, 610-618. [CrossRef]

8. Argyrakopoulou, G.; Dalamaga, M.; Spyrou, N.; Kokkinos, A. Gender Differences in Obesity-Related Cancers. Curr. Obes. Rep. 2021, 10, 100-115. [CrossRef]

9. Peters, S.A.E.; MacMahon, S.; Woodward, M. Obesity as a risk factor for COVID-19 mortality in women and men in the UK biobank: Comparisons with influenza/pneumonia and coronary heart disease. Diabetes Obes. Metab. 2021, 23, 258-262. [CrossRef]

10. Su, Z.; McDonnell, D.; Roth, S.; Li, Q.; Šegalo, S.; Shi, F.; Wagers, S. Mental health solutions for domestic violence victims amid COVID-19: A review of the literature. Glob. Health 2021, 17, 67. [CrossRef]

11. Su, Z.; Cheshmehzangi, A.; McDonnell, D.; Šegalo, S.; Ahmad, J.; Bennett, B. Gender inequality and health disparity amid COVID-19. Nurs. Outlook 2021. [CrossRef]

12. Bradbury-Jones, C.; Isham, L. The pandemic paradox: The consequences of COVID-19 on domestic violence. J. Clin. Nurs. 2020, 29, 2047-2049. [CrossRef]

13. Carter, S.J.; Baranauskas, M.N.; Fly, A.D. Considerations for obesity, vitamin D, and physical activity amid the COVID-19 pandemic. Obesity 2020, 28, 1176-1177. [CrossRef]

14. Yu, W.; Rohli, K.E.; Yang, S.; Jia, P. Impact of obesity on COVID-19 patients. J. Diabetes Its Complicat. 2020, 35, 107817. [CrossRef]

15. Robinson, E.; Boyland, E.; Chisholm, A.; Harrold, J.; Maloney, N.G.; Marty, L.; Mead, B.R.; Noonan, R.; Hardman, C.A. Obesity, eating behavior and physical activity during COVID-19 lockdown: A study of UK adults. Appetite 2021, 156, 104853. [CrossRef]

16. Callow, D.D.; Arnold-Nedimala, N.A.; Jordan, L.S.; Pena, G.S.; Won, J.; Woodard, J.L.; Smith, J.C. The mental health benefits of physical activity in older adults survive the COVID-19 pandemic. Am. J. Geriatr. Psychiatry 2020, 28, 1046-1057. [CrossRef]

17. Meyer, J.; McDowell, C.; Lansing, J.; Brower, C.; Smith, L.; Tully, M.; Herring, M. Changes in physical activity and sedentary behavior in response to COVID-19 and their associations with mental health in 3052 US adults. Int. J. Environ. Res. Public Health 2020, 17, 6469. [CrossRef]

18. López-Bueno, R.; Calatayud, J.; Ezzatvar, Y.; Casajús, J.A.; Smith, L.; Andersen, L.L.; López-Sánchez, G.F. Association between current physical activity and current perceived anxiety and mood in the initial phase of COVID-19 confinement. Front. Psychiatry 2020, 11, 729. [CrossRef]

19. Cheval, B.; Sivaramakrishnan, H.; Maltagliati, S.; Fessler, L.; Forestier, C.; Sarrazin, P.; Orsholits, D.; Chalabaev, A.; Sander, D.; Ntoumanis, N.; et al. Relationships between changes in self-reported physical activity, sedentary behaviour and health during the coronavirus (COVID-19) pandemic in France and Switzerland. J. Sports Sci. 2020, 39, 699-704. [CrossRef]

20. World Health Organization. Physical Activity. Available online: https://www.who.int/news-room/fact-sheets/detail/physicalactivity (accessed on 3 December 2021).

21. Westerterp, K.R. Changes in physical activity over the lifespan: Impact on body composition and sarcopenic obesity. Obesity Rev. 2018, 19, 8-13. [CrossRef]

22. Ainscough, K.M.; O’Brien, E.C.; Lindsay, K.L.; Kennelly, M.A.; O’Sullivan, E.J.; O’Brien, O.A.; McCarthy, M.; De Vito, G.; McAuliffe, F.M. Nutrition, behavior change and physical activity outcomes from the PEARS RCT-An mHealth-supported, lifestyle intervention among pregnant women with overweight and obesity. Front. Endocrinol. 2020, 10, 938. [CrossRef]

23. Lin, C.-H.; Chiang, S.-L.; Yates, P.; Lee, M.-S.; Hung, Y.-J.; Tzeng, W.-C.; Chiang, L.-C. Moderate physical activity level as a protective factor against metabolic syndrome in middle-aged and older women. J. Clin. Nurs. 2015, 24, 1234-1245. [CrossRef]

24. Schuch, F.B.; Bulzing, R.A.; Meyer, J.; Vancampfort, D.; Firth, J.; Stubbs, B.; Grabovac, I.; Willeit, P.; Tavares, V.D.O.; Calegaro, V.C.; et al. Associations of moderate to vigorous physical activity and sedentary behavior with depressive and anxiety symptoms in self-isolating people during the COVID-19 pandemic: A cross-sectional survey in Brazil. Psychiatry Res. 2020, $292,113339$. [CrossRef]

25. Guthold, R.; Stevens, G.A.; Riley, L.M.; Bull, F.C. Worldwide trends in insufficient physical activity from 2001 to 2016 : A pooled analysis of 358 population-based surveys with 1.9 million participants. Lancet Glob. Health 2018, 6, e1077-e1086. [CrossRef]

26. Guthold, R.; Ono, T.; Strong, K.L.; Chatterji, S.; Morabia, A. Worldwide variability in physical inactivity: A 51-country survey. Am. J. Prev. Med. 2008, 34, 486-494. [CrossRef]

27. Mayo, X.; Liguori, G.; Iglesias-Soler, E.; Copeland, R.J.; Clavel San Emeterio, I.; Lowe, A.; del Villar, F.; Jimenez, A. The active living gender's gap challenge: 2013-2017 Eurobarometers physical inactivity data show constant higher prevalence in women with no progress towards global reduction goals. BMC Public Health 2019, 19, 1677. [CrossRef]

28. Ajzen, I. The theory of planned behavior. Organ. Behav. Hum. Decis. Processes 1991, 50, 179-211. [CrossRef]

29. Janz, N.K.; Becker, M.H. The Health Belief Model: A decade later. Health Educ. Q. 1984, 11, 1-47. [CrossRef]

30. Rosenstock, I.M. Historical origins of the health belief model. Health Educ. Monogr. 1974, 2, 328-335. [CrossRef]

31. Fishbein, M. A theory of reasoned action: Some applications and implications. Neb. Symp. Motiv. 1979, $27,65-116$. 
32. Kreuter, M.W.; Wray, R. Tailored and targeted health communication: Strategies for enhancing information relevance. Am. J. Health Behav. 2003, 27, S227-S232. [CrossRef]

33. Hawkins, R.P.; Kreuter, M.; Resnicow, K.; Fishbein, M.; Dijkstra, A. Understanding tailoring in communicating about health. Health Educ. Res. 2008, 23, 454-466. [CrossRef]

34. Su, Z.; Mackert, M.; Li, X.; Han, J.; Crook, B.; Wyeth, B. "Study Natural" without drugs: An exploratory study of theory-guided and tailored health campaign interventions to prevent nonmedical use of prescription stimulants in college students. Int. J. Environ. Res. Public Health 2020, 17, 4421. [CrossRef]

35. Su, Z.; Zeng, C. The effects of health consideration on exergaming behavior in college students: A structural equation perspective Res. Q. Exerc. Sport 2020, 1-9. [CrossRef]

36. Furnham, A.; Badmin, N.; Sneade, I. Body image dissatisfaction: Gender differences in eating attitudes, self-esteem, and reasons for exercise. J. Psychol. 2002, 136, 581-596. [CrossRef]

37. Homan, K.J.; Tylka, T.L. Appearance-based exercise motivation moderates the relationship between exercise frequency and positive body image. Body Image 2014, 11, 101-108. [CrossRef]

38. Mears, D.; Hansen, L. Technology in physical education article \#5 in a 6-part series: Active gaming: Definitions, options and implementation. Strategies 2009, 23, 26-29. [CrossRef]

39. Oh, Y.; Yang, S. Defining exergames \& exergaming. In Proceedings of the Meaningful Play 2010 Conference Proceedings, East Lansing, MI, USA, 21-23 October 2010; pp. 1-17.

40. Dasso, N.A. How is exercise different from physical activity? A concept analysis. Nurs. Forum 2019, 54, 45-52. [CrossRef]

41. Kakinami, L.; O'Loughlin, E.K.; Dugas, E.N.; Sabiston, C.M.; Paradis, G.; O'Loughlin, J. The association between exergaming and physical activity in young adults. J. Phys. Act. Health 2015, 12, 789-793. [CrossRef]

42. Godin, G.; Shephard, R.J. A simple method to assess exercise behavior in the community. Can. J. Appl. Sport 1985, 10, 141-146.

43. Munro, B.H. Statistical Methods for Health Care Research; Lippincott, Williams \& Wilkins: Philadelphia, PA, USA, 2005.

44. Cerny, B.A.; Kaiser, H.F. A study of a measure of sampling adequacy for factor-analytic correlation matrices. Multivar. Behav. Res. 1977, 12, 43-47. [CrossRef]

45. Bartlett, M.S. A note on the multiplying factors for various $\chi 2$ approximations. J. R. Stat. Soc. 1954, 16, 296-298. [CrossRef]

46. DeVellis, R.F. Scale Development: Theory and Applications, 2nd ed.; SAGE Publications: Thousand Oaks, CA, USA, 2003.

47. Heise, L.; Greene, M.E.; Opper, N.; Stavropoulou, M.; Harper, C.; Nascimento, M.; Zewdie, D.; Darmstadt, G.L.; Greene, M.E.; Hawkes, S.; et al. Gender inequality and restrictive gender norms: Framing the challenges to health. Lancet 2019, 393, 2440-2454. [CrossRef]

48. Mauvais-Jarvis, F.; Bairey Merz, N.; Barnes, P.J.; Brinton, R.D.; Carrero, J.-J.; DeMeo, D.L.; De Vries, G.J.; Epperson, C.N.; Govindan, R.; Klein, S.L.; et al. Sex and gender: Modifiers of health, disease, and medicine. Lancet 2020, 396, 565-582. [CrossRef]

49. Su, Z.; McDonnell, D.; Ahmad, J.; Cheshmehzangi, A.; Xiang, Y.T. Mind the "worry fatigue" amid Omicron scares. Brain Behav. Immun. 2021, 101, 60-61. [CrossRef]

50. Reddick, R. On Zoom, Men Don't Like Feeling Watched and Judged-But Women Are Used to It. Available online: https: / / theconversation.com/on-zoom-men-dont-like-feeling-watched-and-judged-but-women-are-used-to-it-150594 (accessed on 22 May 2021).

51. Tulshyan, R. Return to Office? Some Women of Color Aren't Ready. Available online: https://www.nytimes.com/2021/06/23 /us/return-to-office-anxiety.html (accessed on 23 December 2021).

52. McKinsey. Seven Charts that Show COVID-19's Impact on Women's Employment. Available online: https://www.mckinsey $\mathrm{com} /$ featured-insights/diversity-and-inclusion/seven-charts-that-show-covid-19s-impact-on-womens-employment (accessed on 23 December 2021)

53. Blomkamp, E. The promise of co-design for public policy. Aust. J. Public Adm. 2018, 77, 729-743. [CrossRef]

54. Baker, M.G.; Wilson, N.; Blakely, T. Elimination could be the optimal response strategy for covid-19 and other emerging pandemic diseases. BMJ 2020, 371, m4907. [CrossRef]

55. Su, Z.; McDonnell, D.; Wen, J.; Cheshmehzangi, A.; Ahmad, J.; Goh, E.; Li, X.; Šegalo, S.; Mackert, M.; Xiang, Y.-T.; et al. Young adults' preferences for influenza vaccination campaign messages: Implications for COVID-19 vaccine intervention design and development. Brain Behav. Immun.-Health 2021, 14, 100261. [CrossRef]

56. Dwyer, M.J.; Pasini, M.; De Dominicis, S.; Righi, E. Physical activity: Benefits and challenges during the COVID-19 pandemic Scand. J. Med. Sci. Sports 2020, 30, 1291-1294. [CrossRef]

57. Maugeri, G.; Castrogiovanni, P.; Battaglia, G.; Pippi, R.; D’Agata, V.; Palma, A.; Di Rosa, M.; Musumeci, G. The impact of physical activity on psychological health during Covid-19 pandemic in Italy. Heliyon 2020, 6, e04315. [CrossRef]

58. Pieh, C.; Budimir, S.; Probst, T. The effect of age, gender, income, work, and physical activity on mental health during coronavirus disease (COVID-19) lockdown in Austria. J. Psychosom. Res. 2020, 136, 110186. [CrossRef]

59. Tison, G.H.; Avram, R.; Kuhar, P.; Abreau, S.; Marcus, G.M.; Pletcher, M.J.; Olgin, J.E. Worldwide effect of COVID-19 on physical activity: A descriptive dtudy. Ann. Intern. Med. 2020, 173, 767-770. [CrossRef]

60. Herbert, C.; Meixner, F.; Wiebking, C.; Gilg, V. Regular physical activity, short-term exercise, mental health, and well-being among university students: The results of an online and a laboratory study. Front. Psychol. 2020, 11, 509. [CrossRef] 
61. Pearson, R.M.; Culpin, I.; Loret de Mola, C.; Quevedo, L.; Murray, J.; Matijasevich, A.; Tilling, K.; Barros, F.C.; Stein, A.; Horta, B.L. Transition to parenthood and mental health at 30 years: A prospective comparison of mothers and fathers in a large Brazilian birth cohort. Arch. Women's Ment. Health 2019, 22, 621-629. [CrossRef]

62. Amudhan, S.; Gururaj, G.; Varghese, M.; Benegal, V.; Rao, G.N.; Sheehan, D.V.; Kokane, A.M.; Chavan, B.S.; Dalal, P.K.; Ram, D.; et al. A population-based analysis of suicidality and its correlates: Findings from the National Mental Health Survey of India, 2015-2016. Lancet Psychiatry 2020, 7, 41-51. [CrossRef]

63. Schaefer, L.M.; Burke, N.L.; Anderson, L.M.; Thompson, J.K.; Heinberg, L.J.; Bardone-Cone, A.M.; Neyland, M.K.H.; Frederick, D.A.; Anderson, D.A.; Schaumberg, K.; et al. Comparing internalization of appearance ideals and appearance-related pressures among women from the United States, Italy, England, and Australia. Eat. Weight. Disord.-Stud. Anorex. Bulim. Obes. 2019, 24, 947-951. [CrossRef]

64. Myre, M.; Glenn, N.M.; Berry, T.R. Exploring the impact of physical activity-related weight stigma among women with selfidentified obesity. Qual. Res. Sport Exerc. Health 2021, 13, 586-603. [CrossRef]

65. Mensinger, J.L.; Meadows, A. Internalized weight stigma mediates and moderates physical activity outcomes during a healthy living program for women with high body mass index. Psychol. Sport Exerc. 2017, 30, 64-72. [CrossRef]

66. Rogowska, A.M.; Pavlova, I.; Kuśnierz, C.; Ochnik, D.; Bodnar, I.; Petrytsa, P. Does physical activity matter for the mental health of university students during the COVID-19 pandemic? J. Clin. Med. 2020, 9, 3494. [CrossRef]

67. Gildner, T.E.; Laugier, E.J.; Thayer, Z.M. Exercise routine change is associated with prenatal depression scores during the COVID-19 pandemic among pregnant women across the United States. PLOS ONE 2020, 15, e0243188. [CrossRef]

68. Santomauro, D.F.; Mantilla Herrera, A.M.; Shadid, J.; Zheng, P.; Ashbaugh, C.; Pigott, D.M.; Abbafati, C.; Adolph, C.; Amlag, J.O.; Aravkin, A.Y.; et al. Global prevalence and burden of depressive and anxiety disorders in 204 countries and territories in 2020 due to the COVID-19 pandemic. Lancet 2021, 398, 1700-1712. [CrossRef]

69. Callaway, E.; Ledford, H. How Bad Is Omicron? What Scientists Know So Far. Available online: https: / /www.nature.com/ articles/d41586-021-03614-z (accessed on 3 December 2021). 